\title{
Phenomenology and functional analysis. A functionalist reading of Husserlian phenomenology
}

\section{Marek Pokropski ${ }^{1}$}

Published online: 11 August 2020

(C) The Author(s) 2020

\begin{abstract}
In the article I discuss functionalist interpretations of Husserlian phenomenology. The first one was coined in the discussion between Hubert Dreyfus and Ronald McIntyre. They argue that Husserl's phenomenology shares similarities with computational functionalism, and the key similarity is between the concept of noema and the concept of mental representation. I show the weaknesses of that reading and argue that there is another available functionalist reading of Husserlian phenomenology. I propose to shift perspective and approach the relation between phenomenology and functionalism from a methodological perspective, specifically taking into account the functionalist explanatory strategy called functional analysis. I discuss the notion of function in Husserl's works and Husserl's idea of functional phenomenology. The key argument I develop is that in functional phenomenology we can find an explanatory strategy which is analogous to the strategy of functional decomposition used in functional analysis. I conclude that the proposed functionalist reading of phenomenology opens a new approach to the integration of phenomenology with cognitive sciences.
\end{abstract}

Keywords Phenomenology · Functionalism · Functional analysis · Decomposition · Functional explanation

\section{Introduction}

Functionalism is recognized as one of the most influential approaches to mind and cognition, usually perceived as incongruent with phenomenological approaches descending from the Husserlian tradition. I think this is misleading, and there are arguments for connections and similarities between these traditions. In philosophy of mind, functionalism may be approached from a number of different perspectives (for an

Marek Pokropski

mpokropski@uw.edu.pl

1 Institute of Philosophy, University of Warsaw, Warsaw, Poland 
overview see e.g. Block 1980). First, as a metaphysical theory of mental states, which argues that to be a mental state is to be a functional state individuated by causal relations to other mental states and inputs and outputs. There are different types of such functionalist theories of mind, including the most popular one: computationrepresentation functionalism. The key idea behind this version of functionalism is that mental states can be understood as Turing machine table states (Putnam 1960) and the mind as a sort of computer program. In this fashion, Dreyfus (Dreyfus and Hall 1982) and McIntyre (1986) proposed computational-functionalist readings of Husserl.

Second, functionalism can be approached as an explanatory strategy called functional analysis, which is applied in psychology and the cognitive sciences. Functional analysis relies on decomposing a cognitive system into component processes and capacities and describing its functional organization (Fodor 1968; Cummins 1975). Functional analysis may differ depending on what type of functionalism one is committed to, and it does not have to necessarily entail computationalism (Piccinini 2010). A proponent of computation-representation functionalism will decompose a target system into a set of specialized computational modules processing input information and returning outputs, and will give an explanation in terms of program execution and data manipulation. But Cummins-style functional analysis, which relies on a more general notion of function as a causal-role, will decompose the system into a set of sub-capacities, which contribute to the system's functioning. These sub-capacities are then described in dispositional-behavioral terms, and not in computational terms.

In the next section, I critically discuss the cognitivist reading of Husserl proposed by Dreyfus and McIntyre, which takes mental representation as the key category. I argue that although there are similarities between computational functionalism and Husserlian phenomenology, they are largely superficial. I outline the deficiencies of Dreyfus' and McIntyre's proposals, one of which is not addressing the notion of function in Husserl. My approach is different and takes the notion of function as a key category. In section 3, I discuss the notion of function in Husserlian phenomenology together with his idea of functional phenomenology. In section 4 , I propose a novel functionalist reading of Husserlian phenomenology. My approach is methodological and takes functionalism primarily as an explanatory strategy. Methodological similarities were already indicated by McIntyre (1986). More recently, Livingston (2005) has argued that there is continuity between the phenomenological and functional methods of conceptual and logical analysis of our experience. My argument is different. The key argument is that in Husserlian "functional phenomenology", as introduced in the first book of Ideas, we find an original notion of intentional function as well as a method of decomposition, which can be understood as analogous to the explanatory strategy of functional analysis. Finally, in section 5, I consider the consequences of my proposal for the naturalization of phenomenology.

\section{Husserlian phenomenology and computational functionalism}

One of the most important insights of phenomenological analyses is that conscious experience is intentional, i.e. it refers to something, it is about something. In contemporary philosophy of mind, the intentional property of mental states is 
often understood in terms of mental representation. In short, a mental state is intentional if and only of it has representational content. The representational interpretation of Husserlian phenomenology was coined in the debate between Hubert Dreyfus (Dreyfus and Hall 1982; Dreyfus 1988) and Ronald McIntyre (1986). Three points are especially important in this representational interpretation of Husserl. First, according to Dreyfus, Husserl's theory of noemata is a predecessor of contemporary computationalism, such as Fodor's representational theory of mind (RTM) (e.g. Fodor 1975). McIntyre disagrees with such a strong computationalist reading, but he acknowledges that there are striking points of agreement between Husserlian phenomenology and contemporary representationalism. Second, the key similarity is that cognition has a mediated character - in Fodor by mental representations, in Husserl by noemata. Third, that in both approaches the theory of mental representations and their role in cognitive processes do not require reference to a mind's physical realization. They are, so to speak, "ontologically neutral".

Arguing that Husserl was a precursor of a sort of representational theory of mind requires the introduction and clarification of some phenomenological terminology including such notions as noema, noematic sense, and noesis.

Husserl introduced the notion of noema in the first book of Ideas (Husserl 1982; especially paragraphs: 87-127). After deploying phenomenological reduction, he considers the nature of the intentionality of consciousness, i.e. how consciousness is directed towards worldly objects, and constates that intentional experience consists of correlated noetic and noematic moments, which he calls, in short, a noesis and noema. It is important to notice that we are not aware of these noetic and noematic moments in the "natural attitude", which is the default mode of our everyday activities. They are components of mental processes in virtue of which consciousness refers to objects, and can be distinguished only by applying phenomenological reduction and attaining the phenomenological attitude. Husserl also emphasizes (Husserl 1982, par. 98) that both types of contents, noetic and noematic, are non-self-sufficient; they belong to each other in the unity of lived experience. This, however, does not mean that the science of noemata is impossible. Husserl clearly states that in virtue of phenomenological reduction and analysis, we can study types of noemata as well as different noetic functions, and ultimately create a general formal theory of noemata. The theory would cover the typology of noetic functions and their noematic correlates, as well as the eidetic laws governing these correlations and building a unity of mental processes (Husserl 1982, par. 93).

In his interpretation of noema, Dreyfus draws from the seminal paper by Dagfinn Føllesdal entitled Husserl's Notion of Noema, where Føllesdal argues that noema should be understood as an abstract unit of sense, i.e. as "an intensional entity, a generalization of the notion of meaning (Sinn, Bedeutung)" (Føllesdal 1969, p. 681). According to Føllesdal, "the noematic Sinn is that in virtue of which consciousness relates to the object" (Føllesdal 1969, p. 682). Therefore, noema is ontologically different from the object to which it refers; it is the conceptual structure through which consciousness can apprehend objects. Another important claim is that noemata are abstract, i.e. they are pure meanings which cannot be perceived as such. Noema is also not a kind of "internal image" of an intended thing 
(this was already ruled out by Husserl in his critique of internal image theory; see Husserl 1982, par. 90). In short, according to this reading, noema is an abstract meaning, which mediates between consciousness and external objects, and in virtue of which cognitive acts have reference. ${ }^{1}$

Understanding noemata as abstract structures mediating cognition is crucial for a representational reading of phenomenology. McIntyre writes: "Husserl's noematic Sinne can be seen - up to a point - as a version of what Fodor calls 'mental representations', having both formal (or 'syntactic') and representational (or 'semantic') properties and so forming a kind of 'language of thought"' (McIntyre 1986, p. 101). But Fodor also believes that the semantic properties of representations can be reduced to their syntax. Here lies the bone of the contention between Dreyfus and McIntyre. Dreyfus claims that for Husserl noemata play mediating role but he adds that they are "formal structures", i.e. "strict rules for possible syntheses" of simple components (Dreyfus and Hall 1982, p. 10-11). If that is the case, then noemata can be considered a result of syntactical operations. In short, noemata are computed similarly to mental representations, and Husserl can be thought to be a formalist who believed in "a mathesis of experience" (Dreyfus 1988, p. 101) and anticipated the computational approach to the mind. McIntyre disagrees on this point and argues that although Husserl acknowledges that noemata have both semantic and syntactic properties, it does not follow that the former are reducible to the later (McIntyre 1986, p. 111). McIntyre is right, and as we will see later, there are more arguments to the effect that Husserl's thinking about mental operations as mathematical was only a loose analogy.

The last point in a representational-functionalist reading of Husserl is "ontological neutrality". Generally speaking, functionalism does not answer the ontological question of what there is. Functionalism answers only the metaphysical question of how mental states are individuated, namely by their function, and functional states are defined by their causal relations to one another and inputs and outputs (Block 2007, p. 19). However, causality is understood in abstraction here, i.e. they are not any specific causal relations, such as those between neurons. Thus, functionalists argue that there can be multiple physical realizations of the same functional state.

McIntyre sees in both Husserl and Fodor opponents of naturalistic psychology. Fodor (1980) adopts a position of "methodological solipsism", which states that in pursuing a theory of mind we should not presuppose anything about the natural setting of the mind or any specific causal relations between mental and physical states. According to McIntyre: "like the functionalists and the computationalists, then, Husserl seeks abstract accounts that would capture what is common to various mental capacities, no matter how different in their natural make-up the entities having these capacities may be" (p. 104). In other words, functionalists, such as Fodor and phenomenologists such as Husserl believe that a theory of mental capacities is independent of their physical realization. Mental states understood as functional states can be physically realized in multiple ways; therefore, to explain the mental

\footnotetext{
${ }^{1}$ This is not the only possible interpretation of Husserl's noema (for an overview, see Drummond 1997). For example, a different reading of noema was proposed by Gurwitsch (2009), who argues for perceptual noema. Perceptual noema, in short, is an adumbration of a thing seen from a certain perspective. Gurwitsch's noema is not abstract and imperceivable, but, on the contrary, is concrete and perceivable. Thus, perception could be conceived as more direct. However, some argue (e.g. Dreyfus 1982) that it is an extension of Husserl's notion of noema, rather than Husserl's original idea.
} 
functioning of a system, we do not have to refer to its physical realization. Thus, theory of mind, which according to Fodor (1974) is a special science, is autonomous from natural sciences such as biology or physics.

Husserl was also critical of reductive naturalistic explanations of consciousness (e.g. Husserl 1964, 2002), because he believed they are based on an erroneous application of the methods of natural science to explain conscious phenomena. Phenomenology, as designed by Husserl, is thought to fill this gap by delivering a method of investigating consciousness and, ultimately, an autonomous and strict science of consciousness, i.e. a science of the general structures of consciousness. According to McIntyre, phenomenological reduction (understood by him as transcendental reduction) plays a similar role to the principle of methodological solipsism. Phenomenological reduction, as a suspension of common beliefs about physical nature and mental phenomena, leads us to a change in attitude from natural to phenomenological. After reduction, our descriptions of mental activities are, in principle, restricted to what is actually experienced. Such purified descriptions of experience are then analyzed in order to discover the structure of a specific experience. Noemata, here understood as a sort of mental representation, can be disclosed only after reduction, and creating a formal theory of noemata does not require reference to brain activity, etc.

Now let us consider the credibility of such a representational reading. Next to the abovementioned similarities there are also differences, some of which might be decisive for the plausibility of such a functionalist reading of Husserl. McIntyre himself indicates several important differences. For example, he acknowledges Husserl's transcendental phenomenology to be in opposition to the psychological level of Fodor's special science of the mind. However, whether this tension is genuine or merely apparent is highly dependent upon our reading of Husserl and his so-called "transcendental turn" (see e.g. Zahavi 2003). It seems to me, that transcendental phenomenology is not the only face of Husserl's phenomenological project, and, furthermore, transcendental phenomenology is not the only way to study consciousness (even if for some phenomenologists it is the most important one). Husserl was aware of that and, although critical of the naturalization of consciousness, acknowledged the importance of experimental psychology. As he writes in the introduction to the first book of Ideas: "My criticism of psychological method did not at all deny the value of modern psychology, did not at all disparage the experimental work done by eminent men. Rather it laid bare certain, in the literal sense, radical defects of method upon the removal of which, in my opinion, must depend an elevation of psychology to a higher scientific level" (Husserl 1982, p. XVIII).

In the lectures entitled Phenomenological Psychology (1977), Husserl shows how to elevate psychology to a phenomenological level. He introduces the idea of eidetic psychology, which was to be a science mediating between transcendental phenomenology and experimental psychology. Eidetic (or phenomenological) psychology is thought to provide experimental psychology with "scientific concepts of internality" (1977, p. 166), which cannot be acquired in an inductive and naturalistic approach, i.e. concepts such as intentionality, noesis and noema, etc.

Husserl characterizes phenomenological psychology as: a priori, eidetic, grounded in intuition or pure description, focusing on intentionality (Husserl 1977, p. 33-34). Phenomenological psychology is a priori science because it is primarily interested in "all those essential universalities and necessities, without which psychological being 
and living are simply inconceivable." It is eidetic because it indicates that "subsequently does it proceed to the explanation of psychological facts, to theory, precisely their eidetic explanation" (p. 33). Intuition designates the source of the a priori. Finally, intentionality states that consciousness is always a consciousness of something. Thus, investigations under the heading of phenomenological psychology concern a twofold aspect: acts of consciousness and related objects of experience, or, to put it in phenomenological terminology, the noetic and the noematic.

Importantly, phenomenological psychology applies a reduction that is different from the transcendental reduction of transcendental phenomenology. Husserl calls it "eidetic reduction" (Husserl 1971) or "phenomenological reduction" (Husserl 1977). Eidetic reduction relies on excluding (suspending) all reference to the physical basis of the mental and all scientific prejudices concerning the physical and the mental. In this way the reduction opens the sphere of the purely psychological to intentional analyses and imaginative variation. The results of these methods are then described, conceptualized, and applied in empirical psychology. According to Kockelmans, phenomenological psychology, although it employs the reduction, remains in the natural attitude (Kockelmans 1987, p. 20), and he maintains that "the purpose of the phenomenological-psychological reduction is not to bring the transcendental subjectivity to light. Phenomenological psychology hopes to expose only the foundations of empirical psychology" (Kockelmans 1987, p. 21). Eidetic reduction makes it possible to see and describe the structures of experience, such as noesis and noema (mental representation), which in the normal attitude are hidden. It can be applied to psychological research, and it does not have to lead to transcendentalism. Phenomenological analysis is therefore theoretical work preceding experimental research. Husserl also suggests that psychological experiments can be useful for phenomenology, thus the relation is mutual (1980, p. 44-45). When we acknowledge this phenomenological middle ground, phenomenology appears to be complementary to psychology rather than opposed to it. As we will see, the difference between transcendental and eidetic reduction is also of key importance for considering the integration of phenomenology with contemporary cognitive science.

Neither Dreyfus nor McIntyre acknowledge the distinction between transcendental phenomenology and phenomenological psychology and the two related types of reduction, thus they stress the opposition between the psychological level and the transcendental level. But McIntyre is also skeptical about the consistency of the phenomenological eidetic approach in general with contemporary cognitive science. He claims that Husserl "takes this phenomenological reflection to be indubitably reliable, and the pronouncements issuing from it are not supposed to be mere speculative or inductive generalizations but necessary or 'eidetic' truths about consciousness. Claims such as these mark radical differences between the methods Husserl characterizes as uniquely phenomenological and those employed by contemporary cognitivists" (McIntyre 1986, p. 103). This seems like a superficial reading of Husserl. The aim of Husserlian phenomenology was to search for certain and apodictic truths about consciousness, but they are not ready to hand. Our access to the structural features of experiences comes in degrees of clarity, and the task of phenomenology is to develop the method and elaborate experiential insights (Husserl 1982, par. 67). For Husserl, such apodictic knowledge is rather an ideal of self-knowledge beyond our capacities, and building a phenomenological science of subjectivity is an infinite task (see e.g. Husserl 1971). 
Phenomenology is not infallible. Already Føllesdal (1988) noticed that Husserl offers an account of the corrigibility of phenomenological observations and statements. As was argued recently, phenomenological eidetic claims can be falsified in at least three ways. First, through intersubjective corroboration (Gallagher and Zahavi 2012, p. 30-31), i.e. a phenomenological description of an experience of a specific type can be compared with others' descriptions of the same type of experience. The result of such corroboration can be either positive, which means that the description captures universal structures of experience, or negative and the description is rejected as erroneous or inconsistent with other descriptions. Second, as Sowa (2012) argues, phenomenological eidetic claims can be falsified in the process of imaginary variation, i.e. by construing in phantasy possible variants of the object of experience, or by reference to "facts of scientific or prescientific experience". If the procedure of variation does not falsify the target claim, then it is acknowledged as a sort of eidetic law "until further notice" (Sowa 2012, p. 259). Third, phenomenological descriptions are, whether we like it or not, confronted with the results of scientific research. For some phenomenologists, scientific experiments may be sufficient evidence to falsify phenomenological claims (e.g. Gallagher and Brøsted Sørensen 2006).

To sum up, both Dreyfus and McIntyre agree that there are striking similarities between Husserlian phenomenology and representational theory of mind as proposed by Fodor. They disagree, however, over the extent of the similarities. Whereas Dreyfus writes that Husserl's theory of intentionality "corresponds exactly" (Dreyfus and Hall 1982 , p. 3) to Fodor's RTM, McIntyre is much more reserved and also stresses essential differences. I agree with McIntyre that Husserl was not a formalist in regard to mental representations and that a strong computationalist reading of his phenomenology is implausible. Both McIntyre and Dreyfus also fail to recognize that there is a further level below the phenomenological transcendental level, that of the eidetic analysis of phenomenological psychology. This distinction is crucial for the functionalist reading of phenomenology and the possibility of integrating it with cognitive science. But there is another issue, which McIntyre and Dreyfus do not address, and it is perhaps the most important one, which every functionalist reading of Husserl should face, concerning the difference in how the notion of function is understood between Husserl and contemporary functionalists.

\section{The notion of function and the idea of functional phenomenology in Husserl}

In this and the following section I develop an alternative functionalist reading of Husserlian phenomenology. I take functionalism primarily as an explanatory strategy. The notion of function is at the center of this approach. My argument is twofold: first, that Husserl used functional terminology and that he introduced an original notion of intentional function responsible for the production of intentional experience. Phenomenology aimed at investigating intentional functions and, more generally, any processes which play a role in constituting experience is referred to as functional phenomenology by Husserl. Second, I argue that functional phenomenology shares similarities with the functionalist explanatory strategy known as functional analysis, which relies on decomposing the system's capacity (explanandum) into a set of functions (explanans) responsible for the capacity. 
In functionalism, a function of system's component is usually understood as the causal role it plays in the system. For example, a mental state of a belief type, e.g. "This cake looks delicious", is in causal relation with other mental states, say a desire ("I want to eat that cake"), and contributes to behavior (eating the cake) assuming that there are no other conflicting states. Causal-role functionalists believe that identifying mental states functionally will allow for formulating law-like generalizations about interactions between them. But as McIntyre rightly states: "Husserl cannot himself be a functionalist of the standard 'causal-role' sort, i.e., he cannot explicate mental states in terms of their causal relations to one another and to the world, for causality (in any naturalistic sense) is 'bracketed' by phenomenological epoché" (McIntyre 1986, p. 104). Physical causality is not something phenomenology investigates. That is why Husserl introduces the notion of motivation to explicate quasi-causal relations between mental states. Motivation is a specific type of mental causation (e.g. Husserl 1977, p. 108). Mental states of different sorts are in motivational relations, which means they can affect each other. For example, a belief can motivate a subject to have a specific emotional state or to perform a particular cognitive act. But the relation of motivation as mental causality is weaker than physical causality. There is no certainty that a mental state will always motivate the same set of other mental states, because the relation depends on a great number of other mental states, their meaning, as well as the context of their occurrence. To put it simply, our mental life is too complex and context dependent to explicate it in strict causal or formal laws, which makes any reading of Husserl as a computational functionalist or causal-role functionalist implausible.

Let us now examine how Husserl was using the concept of function. It is important to notice that the notion of function appears in Husserl's works very early. Before his phenomenological period, in Philosophy of Arithmetic (Husserl 1891/2012) he was especially interested in methods of constructing numerical systems and discussed arithmetical operations concerning both the numerical construction of complex expressions as well as the reduction of complex expressions to normal form. According to Stefania Centrone (2010, p. 316, 330), in this period Husserl used the procedural notion of function, i.e. function as a numeric procedure, as a rule, prescription or an algorithm in a general sense. For example, a numeric procedure takes one or more arguments and returns a numeric product, i.e. a complex term.

In the first book of Ideas, Husserl proposes his own original notion of intentional function understood as a mental operation of constitution, i.e. production of object experience, and introduces the idea of functional phenomenology. In paragraph 86 of Ideas I, he writes:

"Nonetheless, the greatest problems of all are the functional problems, or those of the 'constitution of consciousness-objectivities'. These problems concern the way in which noeses, e.g. with respect to Nature, by animating stuff and combining it into manifold-unitary continua and syntheses bring about consciousness of something such that the Objective unity of the objectivity allows of being harmoniously 'made known', 'legitimated' and 'rationally' determined.

In this sense 'function' (in an entirely different sense in contrast to the mathematical one) is something wholly unique, grounded in the pure essence of noesis. Consciousness is precisely consciousness 'of' something; it is of its 
essence to bear in itself 'sense', so to speak, the quintessence of 'soul', 'spirit', 'reason'. Consciousness is not a name for 'psychological complexes', for 'contents' fused together, for 'bundles' or streams of 'sensations' which, without sense in themselves also cannot lend any 'sense to whatever mixture;"

and he adds at the end of the paragraph:

"Not only with regard to the difficulties which it arrives at, but also with regard to the ranking of problems from the standpoint of the idea of an absolute cognition, [pure hyletic phenomenology] obviously stands far below the noetic and functional phenomenology (both of which, moreover, are properly not to be separated)." (Husserl 1982, par. 86)

In this rich passage we see that Husserl identifies functional problems with problems of object constitution or, to use the language of early Husserl, object construction. An object experience is a product of functions Husserl called noeses and their noematic correlates. The "stuff" here is understood as hyle or sense-data, which is formed by the noetic functions. Noetic functions take the data on the one hand and noematic representations on the other and produce an object experience. The concept of noetic function might seem similar, to some extent, with the procedural understanding of function Husserl considered in the context of numeric systems. If that is the case, then the computational reading of phenomenology would gain a new argument. However, Husserl explicitly states that his concept of function is completely different than the mathematical one. In the cited paragraph, we do not see any justification for why he rejects the mathematical meaning of function in the phenomenological domain, but there are at least two good reasons for doing so.

First, already in the Philosophy of Arithmetic, Husserl notices that calculations operate on signs not on meanings, and therefore we can distinguish two separate but connected structures: a conceptual one and a signitive one (Centrone 2010, pp. 330-331). Arithmetical operations, i.e. computations, concern the latter - they are operations on signs, which can be considered without reference to their meaning. They are syntactical operations of putting together signs and constructing complex terms or, conversely, deconstructing complex terms into simple ones. But, as Husserl states in the cited paragraph, consciousness bears itself a 'sense', meaning, or, in other words, semantics, and thus reducing mental functions to arithmeticsyntactic functions is implausible.

Second, Husserl sees the limitations of using a mathematical analogy in a phenomenological context. Phenomenology is not a mathematics of consciousness, because it is a different type of exact science. Furthermore, applying mathematical methods to consciousness is a "misleading prejudice" (Husserl 1982, p. 169-170), which results in the crisis of scientific reason (Husserl 1970). According to Husserl, phenomenology is, similarly to mathematics, an eidetic science, but contrary to mathematics, which investigates "formal essences", it investigates "material essences", i.e. essences apprehended in intuition, which in the Logical Investigations Husserl calls "inexact essences" (Husserl 2001, Investigation III, par. 9). These "inexact essences" require a different methodology and conceptual apparatus. In order to explicate these essences, phenomenology uses descriptive notions that differ from the idealized notions of 
mathematics. What is more, the laws that phenomenology discovers are of a different nature than the strict laws of mathematics. Husserl also doubts that we can recognize phenomenological axioms, analogous to geometric axioms, because the variety of the forms of mental phenomena is potentially infinite (Husserl 1982, par. 72-73). It seems, therefore, that although the mathematical understanding of function was Husserl's initial inspiration, it was ultimately abandoned in pursuit of phenomenology.

Interestingly, Husserl also seems to reject the psychological notion of function understood here as the procedure of synthesizing sensations into "psychological complexes". Although in a footnote Husserl remarks that such a notion of psychological function is used in Carl Stumpf's "hyletic phenomenology" (Husserl 1982, p. 210), it can also be attributed to experimental psychology, which Husserl criticized. Experimental psychology cannot explain intentionality and has to be grounded in phenomenological psychology. As Husserl writes: "All uniting takes place here by means of the functions of apprehension which make of the sense-data appearances of'(Husserl 1977, p. 126). These are intentional functions and their noematic correlates, which make an adumbration an adumbration of something. Functional phenomenology, which employs analysis of intentional structures, can be conceived as part of the abovementioned phenomenological eidetic psychology, which precedes empirical psychology and provides it with a genuine analysis of intentionality. In the following, I will argue that functional phenomenology shares similarities with the explanatory strategy called functional analysis.

\section{Functional analysis and phenomenological decomposition}

Functional analysis, in the broadest sense, is a method of explaining a system's capacities in functional terms. It relies on the decomposition of the target system's capacities into a set of sub-capacities (functions), and is usually followed with a sketch of the system's functional architecture. There are different types of functional analysis depending on the type of functionalism. For instance, Piccinini and Craver (2011) distinguish three types of such analysis: functional analysis by internal states, so-called boxology and task analysis. Computational functionalism's preferred form of explanation is functional analysis by internal states, since it explains the target capacity using a set of internal states and their relations to each other and to inputs and outputs. Internal states can be described in representational terms and their manipulation as computations. The form of analysis called boxology is associated with Fodor's idea of the mind's modularity. It encapsulates cognitive functions and subfunctions in specialized modules. According to Fodor, modules are a system's components; however, they are distinguished through functional rather than structural description. In the complete explanation, the target system is represented in a schematic form of boxes and arrows, in which boxes represent specific functional modules and arrows depict relations between them.

Finally, there is functional analysis as task analysis (Cummins 1975, 2000). Cummins not only describes the explanatory strategy, but he also argues that the nature of psychological explanation is functional. This type of functional analysis can be divided roughly into three steps. First, we identify the explanandum phenomenon, which in the case of cognitive psychology is one of the target system's cognitive 
capacities. Then we define the capacity in dispositional terms, i.e. the system's cognitive capacity $\varphi$ is a complex dispositional property $\mathrm{D}$, which means that the system exhibits a law-like regularity in its behavior. According to Cummins, the best way to explain this kind of dispositional property is decomposition of the disposition D into a set of sub-dispositions $\mathrm{d} 1, \mathrm{~d} 2, \ldots, \mathrm{d} n$. The final step is representing the system's target capacity decomposed in functional analysis in a form of functional design. The functional design represents the system's functional architecture, which, according to Cummins, explains the target phenomenon.

Now considering Husserl's functional phenomenology, one could ask whether it employs any of these types of functional analysis. Boxology seems not to have much in common with the phenomenological approach. Proponents of a computationalfunctionalist reading, such as Dreyfus, would see in Husserlian phenomenology the analysis by internal states expressed in representational terms, i.e. as noemata, which are then computed. But as I argued above, a strong computationalist reading of Husserl seems implausible.

At first glance, the main difference between phenomenology and functional task analysis is also the understanding of function. In Husserl, the central notion is intentional function, i.e. functions responsible for different sorts of intentional unity of experience. For Cummins (1975), something has a function in the system if it contributes to the system's capacity. But on a certain level of abstraction, these approaches seem quite similar. For example, a perceptual apprehension of an object, which is a paradigmatic case of perceptual intentionality for Husserl, can also be considered a capacity. Furthermore, both approaches identify functions with relevancy for the target capacity, so, for instance, following Husserl one can argue that functions of bodily motility contribute to the constitution of the experience of spatial orientation (Husserl 1997). The difference is found, however, in a deeper understanding of this relevancy. For Cummins, it would be causal relevancy; for Husserl, as I argued above, causal relations are replaced by motivational relations. Motivational relations are law-like; however, they differ from causal or strict formal laws. Rather than focusing on one particular type of relevance, I propose to instead rely on the more general notion of constitutive relevancy. A function is constitutively relevant to the target phenomenon (a capacity), if it contributes to its occurrence. We abstract, however, from establishing the specific nature of this relevancy.

The key similarity between functional analysis and functional phenomenology is that they both employs decomposition explanatory strategy. Functional phenomenology employs its own type of decomposition strategy, i.e. decomposition of unitary experience into its contents and constitutive functions. On the one hand, it fragments and categorize the contents of experience; on the other hand, it identifies representational functions.

\subsection{Phenomenological decomposition}

One of the key ideas in phenomenology is that in the naïve attitude we encounter objects in the world, which are, so to speak, ready-made. The task of phenomenology is to break down this naivety and explain how objects of experience are constituted in the activity of consciousness. Applying the reductive method is the first step. What is next is the process of analyzing an experience in order to extract 
its structures. Taking into account the idea of functional phenomenology, I argue that it employs a method which relies on decomposing an experience into its noematic contents and related functions involved in the production of experience. I call this type of decomposition static, since it is closely related to the idea of static phenomenology, later developed into the genetic approach.

Static decomposition is, relatively speaking, the simplest and most intuitive way to analyze experience, and it is already present in Husserl's early works, where he employs the procedure of fragmenting objects of experience. In Logical Investigations, he writes: "The division of a whole into a plurality of mutually exclusive pieces we call a piecing or fragmentation (Zerstückung) of the same" (Husserl 2001, p. 29). In the third investigation, he develops a general mereological theory of wholes and parts, and specifically he discusses piecing experiences, i.e. phenomenological contents.

There is no space here for a detailed discussion of this complex mereological theory, so I will mention only its main ideas. The key distinction introduced at the beginning of the investigation is the distinction between independent and "non-independent" parts. A part is anything that can be distinguished in an object (Husserl 2001, p. 5, 29). An independent part can also be called a piece (or portion), since it can be a separate object of analysis. A dependent part is tied to other contents and cannot be separated in reality, only in abstraction. Sometimes Husserl also calls a dependent part a moment or an abstract part. Moreover, each part can be composed of other parts, thus it can also be decomposed; the whole procedure of decomposition is iterative and assumes the existence of different levels of decomposition. Husserl also introduces the relation of foundation: "A content of the species A is founded upon a content of the species B, if an A can by its essence (i.e. legally, in virtue of its specific nature) not exist, unless a B also exists ..." (Husserl 2001, p. 34). The relation of foundation is important because it expresses the necessary (a priori necessity based on "material essences") relations between parts and wholes.

Let us consider an example of the perception of an apple tree. First, we see the tree's shape, the colors of its trunk, leaves and fruits. When we touch its bark, we experience shapes, texture and temperature. We can also sense the smell of the fruits and hear the leaves rustle in the wind. All these sensory contents are parts of the unitary experience of an apple tree. Some of them are independent parts and can be analyzed as separate pieces, others are non-independent (or abstract parts) because they need to be analyzed in reference to one another. For instance, we can consider the shape of a leaf separately, but a color cannot exist without a shape, and the tactile experience of texture without extension. When we move around the object, the shape, the size of the parts and the colors vary - these are partial moments of the perceptual experience. The whole experience of the tree can be thus divided into different aspects containing different sensory as well as representational contents.

A more recent example of the decomposition of the contents of experience can be found in the micro-phenomenological studies of first-person experience by Petitmengin et al. (2019). The first-person descriptions from micro-phenomenological interviews are analyzed and decomposed in order to extract the structure of the studied experience. The structural features are of two dimensions: synchronic (configuration of experiential contents at a given moment) and diachronic (evolution of the experiential contents over time).

What is especially interesting for us here is that the decomposition of contents is supplemented in Husserl with the decomposition of noetic functions. Units of 
meaning, or noemata in Husserlian terminology, identified in the decomposition of contents are related to noetic functions. Thanks to noetic functions, sensory contents are correlated with noematic (e.g. conceptual) contents, which can then be expressed in the form of judgements. To put it differently, noetic functions play the role of representational functions, which give meaning to sense-data by correlating it with mental representations.

But Husserl was not satisfied with static decomposition. It was too formal and blind to other than conceptual yet essential processes, which contributes to the experience. Husserl saw that the simple dichotomy of sensory matter and noetic form did not cover the whole process of the production of experience. He recognized that the level of intentional functions related to the ego's activity is just one amongst several levels of constitution, including the level of passive synthesis. In order to explain the active as well as passive synthesis of experience, Husserl develops the idea of genetic phenomenology, which aims to explain the genesis of the very process of constitution. As he writes in a short essay entitled Static and Genetic Phenomenological Method:

"In a certain way, we can therefore distinguish 'explanatory' phenomenology as a phenomenology of regulated genesis, and 'descriptive' phenomenology as a phenomenology of possible, essential shapes (no matter how they have come to pass) in pure consciousness and their teleological ordering in the realm of possible reason under the headings, 'object' and 'sense.' In my lectures, I did not say 'descriptive,' but rather 'static' phenomenology. The latter offers an understanding of intentional accomplishment, especially of the accomplishment of reason and its negata. It reveals to us the graduated levels of intentional objects that emerge in founded apperceptions of a higher level as objective senses and in functions of sense giving, and it reveals to us how they function in them, etc." (Husserl 1998, p. 629)

According to Husserl, the static approach, which describes the constitution of an intentional object as "the product of an objectivating operation of the ego" (Husserl 1973, p. 72), should be supplemented by a genetic investigation which explains the passive processes accompanying and influencing the acts of the ego. By active level of constitution, Husserl understands all processes which are related to cognitive activities and are accessible to awareness, so, for example, all contents which are attentively intended in perception and expressed in acts of judgement. Noemata understood as linguistic meanings, or as mental representations, are part of this active synthesis. The passive level of constitution concerns processes which are not related to cognitive acts but that still influence the contents of experience. For example, that includes the processes of different sorts of associations: affectivity, kinesthesis and previous experiences, which motivationally effect occurrent lived experience (see e.g. Welton 1982). So genetic phenomenology enriches the static picture of hyletic content shaped by the noetic activity. It discloses that under noetic functions there are motivational and associative functions, which also contribute to our experience.

The shift from static to genetic analysis in Husserl's work can be seen in the development of his model of time-consciousness (Husserl 1991; for an overview see e.g. Kortooms 2002; Landgrebe 1981; Warren 2009). A simple static model of timeconsciousness consists of intentional functions engaged in the production of a unitary 
experience of a temporal object (e.g. a melody). The general cognitive capacity to produce the experience can be divided into three subfunctions, which are retention (retaining in consciousness parts of the object which are no longer present), protention (anticipating the parts of the object which are not yet present) and primal-impression (sensory receptivity in the present moment). According to Husserl, we do not experience the momentary "now" of a temporal object as sensorially stimulating, but the experience of "now" is a product of all these functions, which means that the sensory core of "now" is always accompanied by retentional-protentional formations. Husserl also divides the retentional function into two subfunctions: the so-called longitudinal retention and transverse retention. The former is directed towards the "how" of the stream of consciousness, namely, into succeeding phases synthesized into a nonobjectified continuity. The latter is directed towards what appears in the flow, i.e., a temporal object.

The static model was later developed by Husserl and supplemented with the genetic approach (Kortooms 2002, p. 175-284). For instance, Husserl includes different functions of affectivity and embodiment in his considerations of the structure of time-consciousness and shows that "the functions of corporeality belong to the functions of the passive pre-constitution" (Landgrebe 1981, p. 56). Another addition to the model were associative functions, i.e. associations with past experiences influencing occurrent experience. Thus, the retentional function as described above was called "near retention", because it is involved with the production of our experience of the living present, it retains the fading phases of perception, e.g. the phases of visual adumbrations of perceptual objects; and for the associative process, Husserl introduced a new term: "far retention" (Rodemeyer 2006, pp. 88-90). Far retention is not limited to the current experience and reaches back to past experiences. It is a form of passive association concerning a given perceived object. Far retention plays an important role in object recognition, i.e. when we recognize an object, it's meaning is enriched by associations with previous experiences of that object.

To sum up, Husserlian phenomenology, as well as some of its contemporary developments, apply an explanatory strategy of decomposition which shares similarities with functional decomposition as applied in functionalism. Phenomenological decomposition has two main levels: the decomposition of experiential contents and related functions. But as Husserl argues, this is merely a descriptive method and it should be supplemented with the explanatory genetic approach. The genetic approach decomposes the passive processes (such as affectivity, embodiment, associations) accompanying the activities of the ego.

\section{Towards functionalist naturalization}

If I am right and functional phenomenology can be read as similar to the functionalist explanatory strategy, it is worth considering the consequences of such a claim for the naturalization of phenomenology. Functionalist naturalization is addressed concisely in the editors' introduction to the volume Naturalizing Phenomenology as a plausible way of non-reductively integrating phenomenology with cognitive science (Roy et al. 1999, pp. 71-72). Two ways of applying functionalist naturalization to Husserlian phenomenology are mentioned. The first one consists in developing Husserlian terminology in 
the direction of functional computationalism. Such interpretations of Husserl were proposed, as we have seen, by Dreyfus and McIntyre. Is the representational reading of phenomenology a plausible approach to naturalization, as Roy et al. hypothesize? McIntyre claims that "neither Fodor nor Husserl - neither cognitive science nor transcendental phenomenology - claims to offer a naturalistic theory about how mental processing actually takes place in human minds or brains" (McIntyre 1986, p. 103). The reason for that is that both positions acknowledge "ontological neutrality". Furthermore, as McIntyre rightly argues, the strong computationalist reading of Husserl is incorrect, because the semantic properties of intentional contents are irreducible to syntactic ones. It seems therefore that another weaker notion of representation is needed to pursue this approach to naturalization.

The second path towards functionalist naturalization is "based on the idea that Husserlian phenomenological descriptions have an intrinsically functional dimension, although not of a computational and causal nature" (Roy et al. 1999, p. 72). The editors of the volume do not develop this idea further and quickly conclude: "the problem is, therefore, to estimate to what extent such a functional dimension of phenomenology can really open the doors to an integration of phenomenological descriptions into a naturalist framework" (p. 72). In this section, I argue that the functional reading of phenomenology proposed above reveals its "functional dimension" and opens a new approach to naturalization.

The idea of functional phenomenology and the method of phenomenological decomposition reveal that there is a functional dimension in phenomenological descriptions. Putting it concisely, functional phenomenology describes and analyzes processes which contribute to experiences of a certain type. Functional phenomenology can be located at the same level as phenomenological psychology, which is different from the transcendental level. In this way we avoid problems with naturalizing of the transcendental and acknowledge the mutual relation between phenomenological theory and empirical research.

But it is still not clear how description of that functional dimension is conducive to naturalization, and how such naturalization should proceed. A short review of the ongoing discussion about the theoretical integration of the cognitive sciences might help in finding an answer (see e.g. Kaplan 2017). By theoretical integration of two or more fields of study, I understand the integration of research from these fields without eliminating or reducing any one of them (Darden and Maull 1977). Theoretical integration is different from the idea of the unification of science (Oppenheim and Putnam 1958); instead of inter-level reduction of one scientific level to another, integrations seeks to create a multi-level pluralistic explanation. An example of such a multilevel approach in cognitive science is the mechanistic model of explanation, according to which different fields of research are integrated if they deliver constraints on the space of possible mechanisms (Craver 2007).

It is a subject of ongoing debate what the status of integrated fields of research is, i.e. whether they are integral parts of one multi-level explanation or if they are distinct yet mutually constraining explanations. Roth and Cummins (2017) argue that functional analysis is a distinct and autonomous explanatory strategy that delivers a functional design of a target system's capacity. The design does not entail structural decomposition, i.e. it does not say anything about how specific functions might map onto the components of a possible physical mechanism. However, as Roth and Cummins 
conclude, the autonomy of functional explanation does not exclude that both functional analysis and mechanism can constrain each other's hypotheses (Roth and Cummins 2017, p. 40). On the contrary, Piccinini and Craver (2011) argue that functional explanations are neither autonomous nor distinct because they lack explanatory power. They can be perceived as incomplete mechanistic explanations. Accordingly, functional analysis delivers a functional sketch of the hypothetical mechanism responsible for the target capacity.

They key notion in this discussion is explanatory autonomy. At first glance, explanatory autonomy seems to be the inverse of reducibility, i.e. properties of one level, say, psychological, are irreducible to properties of another level, say, neurobiological, and thus the psychological level is autonomous. But this notion of autonomy was invented at a time when the covering-law model of explanation was dominant together with the idea of nomological reduction and the unification of science. A different definition of autonomy has been proposed in the discourse surrounding the explanatory integration of cognitive science: autonomy can be understood as the independence of a scientific discipline in several domains. "One scientific enterprise may be called autonomous from another if the former can choose (i) which phenomena to explain, (ii) which observational and experimental techniques to use, (iii) which vocabulary to adopt, and (iv) the precise way in which evidence from the other field constrains its explanations" (Piccinini and Craver 2011, p. 288). The last domain is crucial for integration.

Kaplan argues that explanatory autonomy can have degrees (Kaplan 2017, p. 3). Accordingly, a scientific discipline can be completely or partially autonomous. For instance, disciplines that investigate the same phenomenon from different points of view are not completely independent in (i) choosing the phenomenon, therefore they are not fully autonomous. Furthermore, it is often the case that the results of one discipline investigating a phenomenon are relevant for another discipline investigating the same phenomenon, and the relevancy can come in the form of mutual constraints. However, their autonomy is maintained in the methods of investigation they choose and the terminology in which their explanations are formulated. For example, chronobiology and computational cognitive science study circadian rhythms using different methods and analytical tools. The former model is grounded in empirical observation and formulated in terms of dynamic systems theory. The latter uses computational modelling in order to propose a hypothetical mechanism responsible for particular behavior. However, by observing mutual constraints, an integrated dynamic-mechanistic model can be achieved (Bechtel and Abrahamsen 2010). Another example comes from explaining mental maladies, such as schizophrenia, which are often informed by research from various fields of research including psychiatry (also phenomenological psychiatry), psychology, sociology, anthropology and, last but not least, neurobiology (e.g. Engel 1977; Kendler et al. 2011). In this respect, these fields of research are not fully independent from one another, but they mutually constrain each other.

Now, let us consider how functional phenomenology could fit into the theoretical integration of cognitive science. First, let us notice that functional phenomenology as an eidetic study of the structures of consciousness is not fully autonomous because there are other fields of research on consciousness and the results from these fields can constrain phenomenology, and vice versa. It is autonomous, however, in choosing its 
own methods of investigating and analyzing mental phenomena, such as decomposition and descriptive terminology. That being said, I do not believe that functional phenomenology can deliver a complete explanation of cognitive capacities on its own. It is unable to address causal relations or the structural organization of underlying mechanisms. It is also limited in terms of experimental research and testing of hypotheses. The key point is, however, the nature of cognitive phenomena, which are complex and multifaced. In order to explain this class of phenomena, an integration of different research fields including phenomenology is required. Phenomenology can significantly contribute to an integrative explanation.

If the integrative framework does not aim to eliminate the descriptions and explanations of the target phenomena proposed by other disciplines but rather seeks multilevel integration of research fields, which constrain each other, then it can be conceived as a non-reductionist strategy for naturalizing phenomenology. The idea of "mutual constraints" (Varela 1996) or "mutual enlightenment" (Gallagher and Brøsted Sørensen 2006) is not new. But the possibility of naturalizing phenomenology depends on what kind of constraints they are.

First, let us notice that a structural description of a target phenomenon already constrains further research. As I argued above, phenomenology in its historical as well as contemporary form can deliver structural (both synchronic and diachronic) descriptions of the explanandum phenomenon. The most persuasive examples come from phenomenological psychiatry, especially from studies of depression (Ratcliffe 2014) and schizophrenia (e.g. Sass 2014). In these cases, phenomenological studies, often supplemented by qualitative methods, managed to deliver descriptions of the maladies that focus on their invariant structures. Such descriptions are not only informative for explanatory purposes but also for therapeutic and diagnostic practice (e.g. Moskalewicz et al. 2018; Parnas et al. 2005).

But my argument goes further. I propose to think of functional phenomenology as an explanatory strategy similar to functional explanations in psychology. Phenomenological decomposition, in an analogous manner to functional decomposition, breaks down the target capacity into a set of functions responsible for producing the experience under study. Let us consider visual perception as a brief example, and then how phenomenological analysis can constrain a functional model of this capacity.

First of all, Husserl notices that although we see material objects, what is actually perceived are an object's adumbrations (Husserl 1982, p. 94). On the one hand, we perceive and recognize the object of perception, and the object's meaning (the noematic core) remains constant. But, on the other, the flow of adumbrations changes in accordance with bodily movements. Importantly, Husserl remarks that the coperceived adumbrations of an object are, to some extent, undetermined, but the indeterminacy can also be reduced by bodily movements, i.e. bodily movements generate new adumbrations, for instance, revealing a side of the object which was previously not in view.

For Husserl, the body is "the organ of perception and is necessarily involved in all perception" (Husserl 1989, p. 61). Visual perception is therefore an embodied process, which is characterized by bodily spatial orientation and constitutes the visual perspective. As Husserl writes, "each thing that appears has eo ipso an orienting relation to the Body, and this refers not only to what actually appears but to each thing that is supposed to be able to appear" (Husserl 1989, p. 61). Another aspect of embodied 
perception is motility. The body is moving and thus it determines (in a motivational sense) the successive adumbrations of a perceived object. At the same time, we feel our body in movement in kinesthetic experience. As Husserl concludes, "we constantly find here this two-fold articulation: kinesthetic sensations on the one side, the motivating; and the sensations of features on the other, the motivated. The like holds, obviously, for touch and, similarly, everywhere. Perception is without exception a unitary accomplishment which arises essentially out of the playing together of two correlatively related functions" (Husserl 1989, p. 63). These two functions constitute an "if-then" system of perception and action, i.e. if my body moves over there, then I will see an object so and so.

Finally, visual perception is, for Husserl, an essentially temporal process (Husserl 1991), i.e. to see a material thing requires, on the one hand, retention of adumbrations already past and, on the other hand, protention of adumbrations which are expected to appear with respect to movement. If the protentional intentionality is fulfilled, i.e. the objects continue to appear as expected, then the perception of objects goes on. When the intention is not fulfilled, then the expectation is not satisfied and the process of perception is interrupted, which can lead, for example, to modification of the meaning of a perceptual object or change in bodily action.

To sum up, the Husserlian analysis of visual experience identifies several key features of visual perception (adumbrations, spatial perspective, temporality) as well as functions involved in the production of experience (sensory receptivity coupled with bodily activity; retention and protention, which constitute a perceptual object in time).

What kind of constraints can we derive from this phenomenological analysis for the cognitive science of vision? On a general level, phenomenology conceives visual perception as an embodied and active process, thus perception should be conceived as coupled with bodily action and dynamic spatial perspective. A more specific constraint concerns the role of retention and protention, which suggest that visual perception consists of cognitive functions of retaining the past content of visual experience and anticipating it in the near future. It was recently argued that these phenomenological constraints are best satisfied by the anticipation-fulfillment (AF) model of visual perception (Madary 2017). The AF model assumes that vision includes constant anticipation and fulfillment (or disappointment) of sensory content as a consequence of self-generated movement (or its neural simulation in the case of an inability to move). On a functional level, the AF model can be described in the Bayesian predictive processing approach (Clark 2013, 2015). Accordingly, anticipation is cashed out in terms of subpersonal inference based on a hierarchical probabilistic model of the world. In short, the system computes the perceptual state that is most likely to be next on the basis of prior probability, the likelihood of the hypothesis, and the input data. The search for the neural mechanisms underlying predictive coding is still at a very early stage, but there are hypotheses concerning cortical processing in feedback connections (e.g. Madary 2017, pp. 123-128).

From the point of view of integrating phenomenology with cognitive science, it is important to establish what kind of constraints phenomenological analysis can provide. The Husserlian account of visual perception is not only a description of the explanandum phenomenon, but it also includes an analysis of the capacity in order to identify relevant cognitive functions. Thus, the constraints which phenomenological analysis provides can be conceived as constraints concerning functionality, which a 
system has to implement in order to exhibit the studied capacity. The example of predictive coding shows that phenomenological constraints can be satisfied by a systemic-functional model. But let me stress that I am not claiming that the predictive processing model corresponds exactly to the phenomenological model. Some authors even contrast these approaches (Zahavi 2017; see Piekarski 2017 for a reply). I only claim that it satisfies some of the functional constraints and shows how perceptual anticipation can possibly be realized at a subpersonal level.

\section{Conclusions}

In the paper I considered two different functionalist interpretations of Husserlian phenomenology. I argued that a strong computational reading of phenomenology is implausible for several reasons. Another functionalist reading of phenomenology, one which I argued for, adopts a methodological perspective and points to the similarities between the explanatory strategy of functional analysis and the phenomenological method of decomposition. I argued that Husserl developed an original notion of intentional function and applied it to decompose experiences and identify the functions responsible for the production of those experiences. According to this interpretation, phenomenological descriptions of the intentional structure of experience can be read as functional descriptions. Finally, I considered the implications of such a functionalist reading for the project of naturalization. I argued that non-reductive naturalization should be understood in terms of providing constraints and that functional phenomenological analyses can fulfil this demand by providing functional constraints on possible functional and mechanical models of underlying mechanisms.

Acknowledgements I wish to thank two anonymous reviewers for their insightful comments and criticisms on earlier versions of this paper.

Funding information This work was supported by the National Science Centre, Poland under Grant 2017/27/B/HS1/00735.

Open Access This article is licensed under a Creative Commons Attribution 4.0 International License, which permits use, sharing, adaptation, distribution and reproduction in any medium or format, as long as you give appropriate credit to the original author(s) and the source, provide a link to the Creative Commons licence, and indicate if changes were made. The images or other third party material in this article are included in the article's Creative Commons licence, unless indicated otherwise in a credit line to the material. If material is not included in the article's Creative Commons licence and your intended use is not permitted by statutory regulation or exceeds the permitted use, you will need to obtain permission directly from the copyright holder. To view a copy of this licence, visit http://creativecommons.org/licenses/by/4.0/.

\section{References}

Bechtel, W., \& Abrahamsen, A. (2010). Dynamic mechanistic explanation: Computational modeling of circadian rhythms as an exemplar for cognitive science. Studies in History and Philosophy of Science, Part A, 41(3), 321-333.

Block, N. (1980). What is functionalism? In Readings in philosophy of psychology (Vol. 1, pp. 171-184). Cambridge: Harvard University Press. 
Block, N. (2007). Consciousness, function, and representation: Collected papers. Bradford.

Centrone, S. (2010). Functions in Frege, Bolzano and Husserl. History and Philosophy of Logic, 31(4), 315336. https://doi.org/10.1080/01445340.2010.511795.

Clark, A. (2013). Whatever next? Predictive brains, situated agents, and the future of cognitive science. Behavioral and Brain Sciences, 36(3), 181-204.

Clark, A. (2015). Surfing uncertainty: Prediction, action, and the embodied mind. Oxford University Press.

Craver, C. F. (2007). Explaining the brain: Mechanisms and the mosaic unity of neuroscience. Oxford: Clarendon Press.

Cummins, R. (1975). Functional analysis. The Journal of Philosophy, 72(20), 741-765. https://oi. org/10.2307/2024640.

Cummins, R. (2000). "How does it work" versus "what are the laws?": Two conceptions of psychological explanation. In F. Keil \& R. A. Wilson (Eds.), Explanation and Cognition (pp. 117-145). Cambridge: MIT Press.

Darden, L., \& Maull, N. (1977). Interfield theories. Philosophy of Science, 44(1), 43-64.

Dreyfus, H. (1982). Husserl's perceptual Noema. In Husserl, intentionality, and cognitive science (pp. 97123). Cambridge: MIT Press.

Dreyfus, H. (1988). Husserl's Epiphenomenology. In H. Otto \& J. Tuedio (Eds.), Perspectives on Mind (pp. 85-101). Reidel.

Dreyfus, H. L., \& Hall, H. (1982). Introduction. In H. L. Dreyfus \& H. Hall (Eds.), Husserl, Intentionality and Cognitive Science (pp. 1-27). Cambridge: MIT Press.

Drummond, J. J. (1997). Noema. In L. Embree (Ed.), Encyclopedia of phenomenology. Springer Netherlands, Heidelberg

Engel, G. (1977). The need for a new medical model: A challenge for biomedicine. Science, 196(4286), 129-136.

Fodor, J. (1968). Psychological explanation. New York: Random House.

Fodor, J. (1974). Special sciences (or: The disunity of science as a working hypothesis). Synthese, 28(2), 97-115.

Fodor, J. (1975). Language of thought. New York.

Fodor, J. (1980). Methodological solipsism considered as a research strategy in cognitive psychology. The Behavioral and Brain Sciences, 3, 63-73.

Føllesdal, D. (1969). Husserl's notion of Noema. The Journal of Philosophy, 66(20), 680-687. https://doi. org/10.2307/2024451.

Føllesdal, D. (1988). Husserl on evidence and justification. In R. Sokolowski (Ed.), Edmund Husserl and the Phenomenological Tradition (pp. 107-129). The Catholic University of America Press.

Gallagher, S., Brøsted Sørensen, J. (2006). Experimenting with phenomenology. Consciousness and Cognition, 15(1), 119-134. https://doi.org/10.1016/j.concog.2005.03.002.

Gallagher, S., Zahavi, D. (2012). The phenomenological mind, 2nd edition. London: Routledge.

Gurwitsch, A. (2009). The structure of perceptual noema. In J. García-Gómez (Ed.), The Collected Works of Aron Gurwitsch (1901-1973) (vol 192, pp. 185-307). Springer, Dordrecht.

Husserl, E. (1891/2012). Philosophy of arithmetic: Psychological and logical investigations with supplementary texts from 1887-1901 (Vol. 10). Springer Science \& Business Media.

Husserl, E. (1964). The Idea of Phenomenology. The Hague (Trans: Alston, W.P.). The Hague, Leiden: M. Nijhoff.

Husserl, E. (1971) "Phenomenology” Edmund Husserl's article for the Encyclopaedia Britannica (1927): New complete translation by Richard E. Palmer, Journal of the British Society for Phenomenology, 2(2), 7790, https://doi.org/10.1080/00071773.1971.11006182.

Husserl, E. (1973). Experience and Judgment. Investigations in a Genealogy of Logic. (Trans: Churchill, J.S, Ameriks, K.). London: Routledge \& Kegan Paul.

Husserl, E. (1977). Phenomenological Psychology. the Hague (Trans: Scanlon, J.). Leiden: Martinus Nijhoff.

Husserl, E. (1982). Ideas pertaining to a pure phenomenology and to a phenomenological philosophy. First book. (trans: F. Kersten). Dordrecht: Springer.

Husserl, E. (1970). The crisis of European sciences and transcendental phenomenology: An introduction to phenomenological philosophy. (trans: Carr). Evanston: Northwestern University press.

Husserl, E. (1989). Ideas pertaining to a pure phenomenology and to a phenomenological philosophy: Second book studies in the phenomenology of constitution (Vol. 3). (trans: Rojcewicz, R., Schuwer, A.). New York: Springer Science \& Business Media.

Husserl, E. (1991). On the phenomenology of the consciousness of internal time (1893-1917). (Trans: Brough, J. B.). Dordrecht: Springer.

Husserl, E. (1997). Thing and space: Lectures of 1907. (trans: Rojcewicz, R.). Dordrecht: Kluwer. 
Husserl, E. (1998). Analyses Concerning Passive and Active Synthesis: Lectures on Transcendental Logic. (trans: Steinbock, A.). J. Springer Netherlands.

Husserl, E. (2001). Logical investigations. vol. 2. (trans.: Findlay, J.N.). London.

Husserl, E. (2002). Philosophy as Rigorous Science. The New Yearbook for Phenomenology and Phenomenological Philosophy II, (trans: Brainard, M.). pp 249-95.

Kaplan, D. M. (2017). Integrating mind and brain science: A field guide. In D. M. Kaplan (Ed.), Explanation and integration in mind and brain science (pp. 1-28). New York: Oxford University Press.

Kendler, K. S., Zachar, P., Craver, C. (2011). What kinds of things are psychiatric disorders? Psychological Medicine, 41(6), 1143-1150.

Kockelmans, J. J. (1987). HusserI's original view on phenomenological psychology. In J. J. Kockelmans (Ed.), Phenomenological psychology: The Dutch school. Dordrecht: Martinus Nijhoff Publishers.

Kortooms, T. (2002). Phenomenology of Time. Edmund Husserl's Analysis of Time-Consciousness. Phaenomenologica, vol 161. Dordrecht: Springer.

Landgrebe, L. (1981). The phenomenology of Edmund Husserl. London: Cornell University Press.

Livingston, P. (2005) Functionalism and logical analysis. In Smith, D.W. \& Thomasson A.L. Phenomenology and Philosophy of Mind. Oxford New York: Oxford University press.

Madary, M. (2017). Visual phenomenology. MIT Press.

McIntyre, R. (1986). Husserl and the representational theory of mind. Topoi, 5(2), 101-113. https://doi. org/10.1007/BF00139224.

Moskalewicz, M., Schwartz, M. A., \& Gozé, T. (2018). Phenomenology of intuitive judgment: Praecoxfeeling in the diagnosis of schizophrenia. Avant, IX, 2, 1-12. DOI: 10.26913/avant.2018.02.04

Oppenheim, P., \& Putnam, H. (1958). Unity of science as a working hypothesis. Minnesota Studies in the Philosophy of Science, 2, 3-36.

Parnas, J., Møller, P., Kircher, T., Thalbitzer, J., Jansson, L., Handest, P., \& Zahavi, D. (2005). EASE: Examination of anomalous self-experience. Psychopathology, 38(5), 236-258.

Petitmengin, C., Remillieux, A., \& Valenzuela-Moguillansky, C. (2019). Discovering the structures of lived experience: Towards a micro-phenomenological analysis method. Phenomenology and the Cognitive Sciences, 18(4), 691-730.

Piccinini, G. (2010). The mind as neural software? Understanding functionalism, Computationalism, and computational functionalism. Philosophy and Phenomenological Research, 81(2), 269-311.

Piccinini, G., \& Craver, C. (2011). Integrating psychology and neuroscience: Functional analyses as mechanism sketches. Synthese, 183(3), 283-311.

Piekarski, M. (2017). Commentary: Brain, mind, world: Predictive coding, neo-Kantianism, and transcendental idealism. Frontiers in Psychology, 8, 2077. https://doi.org/10.3389/fpsyg.2017.02077.

Putnam, H. (1960). “Minds and Machines.” In S. Hook, (Ed.), Dimensions of mind. New York: University Press.

Ratcliffe, M. (2014). Experiences of depression: A study in phenomenology. OUP Oxford.

Rodemeyer, L. (2006). Intersubjective temporality. It's about time. Dordrecht: Springer.

Roth, M., \& Cummins, R. (2017). Neuroscience, psychology, reduction, and functional analysis. In D. M. Kaplan (Ed.), Explanation and integration in mind and brain science (pp. 29-43). New York: Oxford University Press.

Roy, J.-M., Petitot, J., Pauchaud, B., \& Varela, F. J. (1999). Beyond the Gap: An Introduction to Naturalizing Phenomenology. In J. Petitot, F. J. Varela, B. Pachoud, \& J.-M. Roy (Eds.), Naturalizing phenomenology: Issues in contemporary phenomenology and cognitive science. Stanford: Stanford University Press.

Sass, L. A. (2014). Explanation and description in phenomenological psychopathology. Journal of Psychopathology, 20, 366-376.

Sowa, R. (2012). Eidetics and its methodology (E. A. Behnke, trans.). In S. Luft \& S. Overgaard (Eds.), The Routledge companion to phenomenology (pp. 254-265). London: Routledge.

Varela, F. (1996). Neurophenomenology: A methodological remedy for the hard problem. Journal of Consciousness Studies, 3(4), 330-349.

De Warren, N. (2009). Husserl and the promise of time: Subjectivity in transcendental phenomenology. Cambridge University Press.

Welton, D. (1982). Husserl's genetic phenomenology of perception. Research in Phenomenology, 12(1), 59-83.

Zahavi, D. (2003). Husserl's phenomenology. Stanford: Stanford University Press.

Zahavi, D. (2017). Brain, mind, world: Predictive coding, neo-Kantianism, and transcendental idealism. Husserl Studies, 34, 47-61.

Publisher's note Springer Nature remains neutral with regard to jurisdictional claims in published maps and institutional affiliations. 